RESEARCH ARTICLE

\title{
ALLELOPATHIC ACTIVITY OF THE RESIDUES OF HERBACEOUS WEED SPECIES COMMON IN ORCHARDS
}

\author{
Siriwardana AJMCM*, Kumarasinghe HKMS and Wathugala DL \\ Department of Crop Science, Faculty of Agriculture, University of Ruhuna, Mapalana, \\ Kamburupitiya, Sri Lanka
}

Received: 15 July 2021: Accepted: 30 October 2021

\begin{abstract}
Cleome viscose L, Andrographis paniculata (Burm. f.) Nees, Ocimum sanctum L. and Celosia argentea L are common herbaceous weed species in orchards with allelopathic activity. This study was conducted to examine the allelopathic effect of residues on seed germination (SG) and growth of indicator plant radish, selected field crops (Eleusine coracana, Vigna radiata, Vigna mungo, Oryza sativa and Vigna unguiculata), and potential autotoxicity. The residue mixtures $(1 \%, 2.5 \%, 5 \%, 10 \%$ and $15 \%)$ were prepared by mixing air-dried ground residues of weeds and sand. The seeds of radish, field crops and the same weed species were planted in different residue mixtures. Complete randomized design with 3 replicates was used for all experiments. The quantitative analysis for allelochemicals was also performed. Except for $1 \%$ of $A$. paniculata, other treatments significantly (p $\leq 0.05)$ inhibited SG of radish and $C$. argentea showed the highest. A varied allelopathic effect on other field crops was observed but $5 \%$ and $10 \%$ of $C$. argentea residues exhibited $100 \%$ inhibition of SG of all field crops excluding paddy. All weed species also showed significant autotoxicity. The presence of the different amounts of total phenolic and flavonoid contents further verified the allelopathic effect of these weed species. These results indicated frequent adding of the residue of the weed species tested in this study would be able to inhibit seed germination and seedling growth of crops tested in this study and the prevalence of the same weed species in the field.
\end{abstract}

Keywords: Allelopathy, Andrographis paniculata, Celosia argentea L., Cleome viscosa L., Ocimum sanctum L.

\section{INTRODUCTION}

Allelopathy is defined as either inhibitory or stimulatory effect of one plant upon another including microorganisms that are caused by the action of chemical compounds referred to as allelochemicals (Reigosa et al. 2006). Furthermore, Allelopathy between plants within the same species (intraspecific allelopathy) is known as auto-allelopathy or autotoxicity (Singh et al. 1999). The allelochemicals are usually secondary plant metabolites or by-products of the principal metabolic pathways in plants (Putnam and Duke 1978). They are non-nutritional and can be synthesized in any plant parts such as leaves, stems, roots, bark, seeds, etc. Under favourable environmental conditions, allelochemicals are released into the environment through volatilization, root exudation, decomposition, and/or leaching Corresponding author: chathura@uciars.cmb.ac.lk
(Latif et al. 2017). Consequently, these chemicals may interfere with a series of physiological and biochemical processes in plants including membrane permeability, water and nutrient uptake, respiration, photosynthesis, protein, and nucleic acid synthesis, and growth regulation in susceptible plants. However, the characteristic visual action of allelochemicals against higher plants includes suppressing seed germination, causing injury to root growth and meristems, or inhibiting seedling growth (Einhellig 1995; Cheng and Cheng 2016).

The allelopathic effect is mainly referred to as a type of negative interaction in the sense of crop production. However, several studies have been reported positive interactions also, depending on the allelochemical considered, the target plant and the concentration tested (Trezzi et al. 2016). Moreover, in agricultural 
context allelochemicals can be produced by crops and weeds. Therefore, attention has been paid to the suppression of weeds by using the allelopathic phenomenon as an innovative weed control method in agriculture. Consequently, that may replace the use of synthetic herbicides to some extent. Allelopathic crops can be used as cover crops or as live mulch, intercrops, or green manures by the means of minimizing biotic stresses such as weed infestation, insect pests, and disease incidents (Farooq et al. 2011). Nevertheless, decomposing residues of such plants also release a considerable amount of secondary metabolites that possess phytotoxic effects on other plants. These chemicals may accumulate and persist at phytotoxic levels in the rhizosphere soil. Finally, that may affect succeeding crops in agricultural lands. To date, about 100,000 plant secondary metabolites have been identified and are classified into 14 classes according to their biosynthetic origin and/or chemical similarity. However, a smaller number of these are described as bioactive allelochemicals including phenolics, terpenoids, glycosteroids, and alkaloids which are important phytochemicals in plant allelopathy (Ahuja et al. 2012; Latif et al. 2017). Several bioassays are used in the evaluation of plant allelopathic potential including aqueous extract screening, seedling screening, field screening, and chemical screening (Ozkan et al. 2019). Generally, the bioassay procedure uses many species to indicate allelopathic activity. Based on sensitivity to phytotoxic chemicals, radish (Raphanus sativus) and lettuce (Lactuca sativa) have been recommended as standard indicator species for the preliminary testing of allelopathic activity (Sharma et al. 2017; Ali 2021). Cleome viscosa (Wal aba), Andrographis paniculata (Kiratha), Ocimum sanctum (Maduruthala), and Celosia argentea (Kirihanda) are common herbaceous weed species occurring in orchards of Sri Lanka with medicinal properties. Furthermore, certain research has discussed most of the medicinal plants may have strong allelopathic activity (Shinwari and Fujii 2013; Baličević et al. 2015). Additionally, Jana and Biswas (2011) reported concentration-dependent inhibitory activity on rice, mustard, and gram seeds germination and growth performances by the root exudates of $C$. viscosa. Nagaraja and Deshmukh (2009) investigated the allelopathic effect of $A$. paniculata on invasive weed species Parthenium hysterophorus in orchards and arable lands. According to Islam and Kato Noguchi (2014) methanol extract of $O$. Sanctum exhibit phytotoxic effect on cress (Lepidium sativum), lettuce (Lactuca sativa), alfalfa (Medicago sativa), italian ryegrass (Loliummulti florum), barnyard grass (Echinochloa crus-galli), and timothy grass (Phleum pratense). C. argentea exhibit allelopathic effect against seed germination and seedling growth of Sorghum bicolor, Phaseolous aureus, Arachis hypogaea, Dolichos lablab, and Vigna unguiculata (Saritha and Sreeramulu 2013).

Hence, this study was aimed to investigate the allelopathic effect of the residues of $C$. viscosa, A. paniculata, $O$. sanctum, and $C$. argentea using radish (indicator plant), some field crops (paddy, finger millet, mungbean, black gram and cowpea) and the selfinhibition (autotoxicity).

\section{MATERIALS AND METHODS Preparation of herbaceous weeds residues}

Herbaceous weed species C. viscosa, $A$. paniculata, $O$. sanctum and $C$. argentea were identified according to the literature explained by Singh et al. (2015); Hossain et al. (2014); Pattanayak et al. (2010); Kengar (2018). And seeds were collected from farmer fields in Matara and Mahiyanganaya area. Then the seeds were planted at the Faculty of Agriculture, University of Ruhuna, Mapalana, Kamburupityta, Sri Lanka.

Above ground parts (stems + leaves) of the four herbaceous weeds were harvested at their blooming stage and dried at room temperature (approx. $28^{\circ} \mathrm{C}$ ) for 10 days. Then residues were ground into small particles using a mechanical grinder and stored in a refrigerator until further use. Three separate bioassay experiments were conducted in a greenhouse with average room temperature to evaluate the allelopathic activity of weed species. Phytochemical analysis was also performed for major plant allelochemicals; phenolic 
acids, flavonoid and alkaloids at the Industrial Technology Institute, Malambe. All the experiments were performed two times with three replications using a randomized complete block design.

\section{Allelopathic effect on indicator plant radish}

Initially, screening the allelopathic potential of residues was tested using an indicator plant radish. The experimental procedures described by Chung and Miller (1995) were followed. Residue mixtures $(1 \%, 2.5 \%, 5 \%$, $10 \%$ ) were prepared by incorporating $3 \mathrm{~g}, 7.5$ $\mathrm{g}, 15 \mathrm{~g}, 30 \mathrm{~g}$ of each residue with $300 \mathrm{~g}$ of silica sand respectively in each pot (diameter $9 \mathrm{~cm}$ and height $10 \mathrm{~cm}$ ). The sand was sieved by a $2 \mathrm{~mm}$ sieve prior to mixing residues. All pots were placed on glass petri dishes to avoid leaching of allelochemicals from the potting mixture, also an equal amount of water was added to each petri dish every other day to maintain adequate moisture. All pots were treated with a fungicide, Mancozeb $80 \% \quad(\mathrm{~W} / \mathrm{W}) \quad \mathrm{WP}$ to prevent fungal contamination before seed sowing. Twenty radish (var. local) seeds were placed uniformly in each pot at 2 weeks after residue incorporation. Control plants were grown in only silica sand. The number of germinated seeds was counted daily from two days after seed placement and was continued up to the completion of seed germination. Seven days after the emergence of seedlings, they were thinned to 10 plants per pot (all seedlings that emerged after 7 days were also removed). Treatments were performed according to the Completely Randomized Design with three replicates. All plants were harvested 20 days after planting. Shoot length, root length and number of leaves were recorded. Dry weight was also taken after drying seedlings at $65^{\circ} \mathrm{C}$ for $8 \mathrm{~h}$. The inhibitory percentage was calculated using equation 01 (eqn1).

\section{Allelopathic effect on other field crops}

The weed species which showed the highest allelopathic effect on radish seed germination and seedling growth was used for this experiment. The procedure followed for this experiment was exactly similar to described above. The field crops used were paddy
Inhibition percentage $(\%)=\left[\frac{(\text { Control-Residue })}{\text { Control }}\right] 100$ ... eqn 1

(Oryza sativa, var. AT 362), finger millets (Eleusine coracana, var. Local), mungbean (Vigna radiata, var. Local), black gram (Vigna mungo, var. Local), and cowpea (Vigna unguiculata, var. Local). Three residue mixture ratios $(5 \%, 10 \%, 15 \%)$ were prepared by mixing $10 \mathrm{~g}, 20 \mathrm{~g}, 30 \mathrm{~g}$ of $C$. argentea (kirihanda) residue with $200 \mathrm{~g}$ of silica sand. Seed germination and plant growth data were recorded as described earlier.

\section{Autotoxicity}

The self-inhibition or autotoxicity was tested following the same procedure explained in the above experiment. Four residue mixtures, $1 \%$, $2.5 \%, 5 \%$, and $10 \%$ were prepared by incorporating $1 \mathrm{~g}, 2.5 \mathrm{~g}, 5 \mathrm{~g}$, and $10 \mathrm{~g}$ of residues from each weed species with $100 \mathrm{~g}$ of silica sand respectively in each pot. Ten seeds from each weed species (C. viscosa, $A$. paniculata, $O$. sanctum, and $C$. argentea) were uniformly placed in pots filled with residues of the same plant species. Finally, the inhibition percentages were calculated as described in earlier experiments.

\section{Phytochemical analysis}

Samples were analyzed for phytochemicals of total phenolic content, total flavonoid content, and total alkaloid. Methanolic extracts (W/V) were prepared by extracting $2 \mathrm{~g}$ of finely ground residues from each species by mixing $30 \mathrm{ml}$ of methanol at room temperature $(25 \pm$ $2^{\circ} \mathrm{C}$ ) for $4-5 \mathrm{hrs}$ with occasional shaking. The extracts were filtered, evaporated, and stored at $-20^{\circ} \mathrm{C}$ until used for analysis (Abeysekera et al. 2017). The total phenolic, flavonoid and alkaloids contents of herbaceous weed residue extracts were determined by the FolinCiocalteu reagent method (Singleton et al. 1999), aluminium chloride method (Siddhuraju and Becker 2003) and Dragendorff's reagent (DR) method (Sreevidya and Mehrotra, 2003) respectively.

\section{Statistical analysis}

The analysis of variance for all data was measured using the general linear model 
procedure of the statistical analysis system (SAS) and mean separation done by Duncan's Multiple Range Test (DMRT). The correlation was performed at the 0.05 probability level using Minitab 14 package.

\section{RESULTS AND DISCUSSION}

Allelopathic effect of herbaceous weed residues on indicator plant radish

Residues of herbaceous weed species and their application rates showed a marked difference in radish seed germination and seedling growth. All the tested residue rates were inhibited seed germination of radish except $1 \%$ of $A$. paniculata and $C$. argentea. Herbaceous weed residues and residue rates showed an interaction effect on inhibition of seed germination of radish. The maximum inhibition percentage of seed germination inhibition (GI \%) resulted in a $10 \%$ residue rate for all herbaceous weed residues except C. viscosa. C. viscosa residues showed around $30-40 \%$ germination inhibition for all concentrations (Fig.1). The highest GI\% for $10 \%$ residue rate was recorded in C. argentea $(100 \%)$ followed by $86.3 \%, 81 \%$, and $40.67 \%$ respectively for $O$. sanctum, $A$. paniculata, and $C$. viscosa residues. Residue rate $1 \%$ of $A$. paniculata stimulated seed germination by $11 \%$.

The highest shoot and root length reduction were observed by $C$. viscosa $10 \%$ residue rate. Meanwhile, $1 \%$ and $2.5 \%$ residue rate of A. paniculata and $1 \%$ residue rate of $O$. sanctum showed stimulation of shoot growth of radish. Further, A. paniculata $2.5 \%$ rate resulted in slight stimulation of root length in radish (Table 1). Significantly highest reduction of the number of leaves $(26.13 \%)$ was occurred in a $10 \% \mathrm{C}$. viscosa residue rate followed by $1 \% O$. sanctum and $5 \% A$. paniculata. While all other treatments showed significant stimulation in the number of leaves per radish seedling. Likewise, significantly highest dry weight reduction also occurred in $10 \%$ C. viscosa residue rate followed by $5 \%$ A. paniculata, $1 \%$ and $5 \%$ of $O$. sanctum and other treatments significantly increased seedling dry weight compared to the control treatment.

\section{Allelopathic effect of Celosia argentea residues on other field crops}

As explained above, $C$. argentea had the highest inhibition percentages on seed germination and growth of radish seedlings. Therefore, the effect of $C$. argentea residues on other field crops (paddy, finger millet, cowpea, mungbean, and black gram) was evaluated. Hundred percent seed germination inhibition percentages were observed in $15 \%$ residue rate for all tested field crops (Fig.2) while it was more than $85 \%$ inhibition in $10 \%$ residue rate. The correlation between seedling growth parameters and residue rates

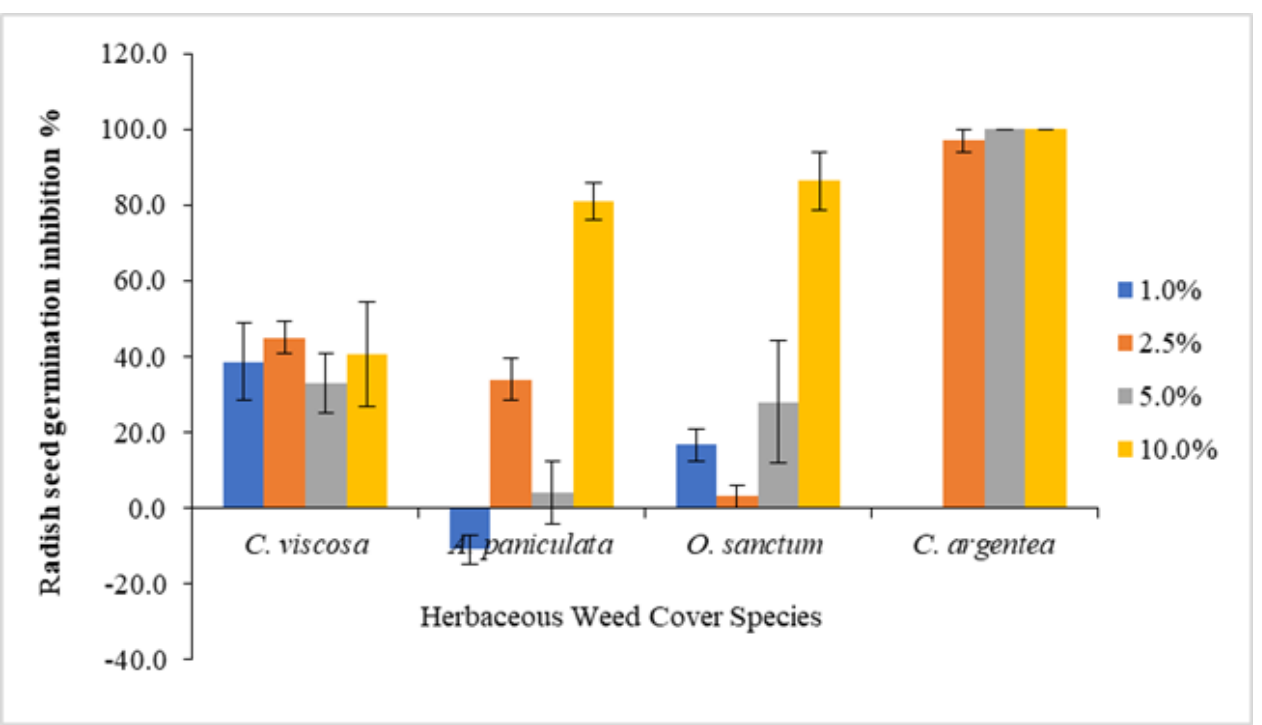

Figure 1: Inhibitory effect of different rates $(1 \%, 2.5 \%, 5 \%$, and $10 \%)$ of herbaceous weed residues on germination percentage of radish 


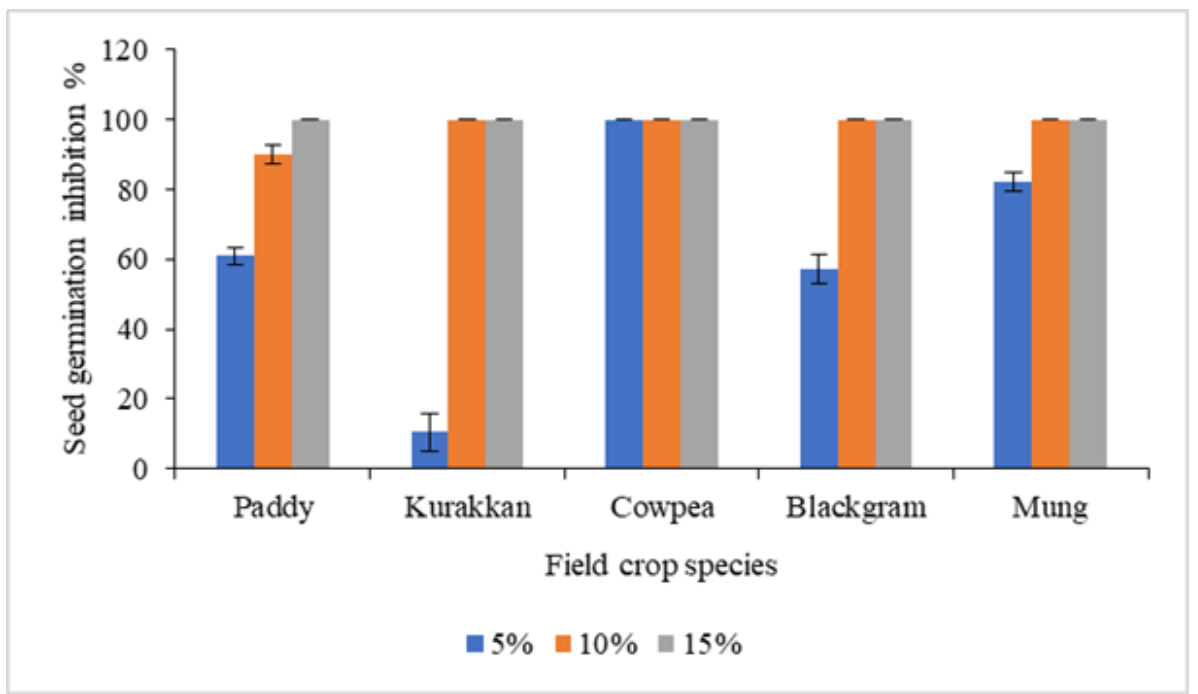

Figure 2: Germination inhibitory effect of $C$. argentea residue on selected field crops. 5\%,10\% and 15\% represent residue rate (Sand: Residue ratio)

for paddy is shown in Fig.3. Where, shoot length $\left(\mathrm{R}^{2}=0.94\right)$, root length $\left(\mathrm{R}^{2}=0.63\right)$, and the number of leaves $\left(\mathrm{R}^{2}=1\right)$ inhibition were positively correlated while dry weight showed a strong negative relationship $\left(\mathrm{R}^{2}=0.95\right)$ with residue rate.

\section{Autotoxicity effect of herbaceous weed residues}

Frequent growth of above mentioned herbaceous weeds in the same crop land and slashing and adding their residues to the land may create autotoxicity effects. Therefore, the autotoxicity of the herbaceous weeds was examined. A significant autotoxicity effect $(p \leq 0.05)$ was observed among herbaceous weed species on the inhibition of seed germination, root length, shoot length, and dry weight. Higher residue rates $(5 \%$ and $10 \%$ ) of all tested species inhibited their seed germination by $100 \%$ (Fig. 4). Lower residue rates were also reduced the seed germination in a considerable percentage. Among 2.5\% residue rate, $A$. paniculata gave $100 \%$ seed germination inhibition and $O$. sanctum gave $96.1 \%$ inhibition followed by $C$. viscosa $(69.4 \%)$ and C. argentea (43.3\%).

Although seed germination percentages are low in low residue rates, a lush stimulus growth was observed in seedlings. Significantly highest shoot length reduction (52.33\%) occurred only by $A$. paniculata $1 \%$ residue rate. All other rates of residues of herbaceous weed species stimulated shoot growth of the same species with significant differences. Similar results were observed in the inhibition percentages of root length, the number of leaves, and dry matter accumulation (Table 1).

\section{Quantitative screening of residues of above- ground plant parts of the herbaceous weeds for major groups of allelochemical} Significantly different total phenolic (TPC) and total flavonoid (TFC) contents were observed in different herbaceous weed species. There were no alkaloids detected at a $10 \mathrm{mg} / \mathrm{ml}$ rate. Significantly highest TPC was found in C. viscosa residue $(65.95 \mathrm{mg} / \mathrm{g})$ followed by $O$. sanctum and $C$. argentea. Similarly, the significantly highest TFC was found in $C$. viscosa residues $(41.69 \mathrm{mg} / \mathrm{g}$ ). However, significantly different TFC amounts were not observed in $C$. argentea and $O$. sanctum. Moreover, A. paniculata showed significantly the lowest TPC and TFC amount (Fig. 5).

The characteristic visual action of allelochemicals against higher plants includes suppressing seed germination, causing injury to root growth and meristems, or inhibiting seedling growth. However, allelochemicals interfere with a series of physiological and biochemical processes in plants. Which 

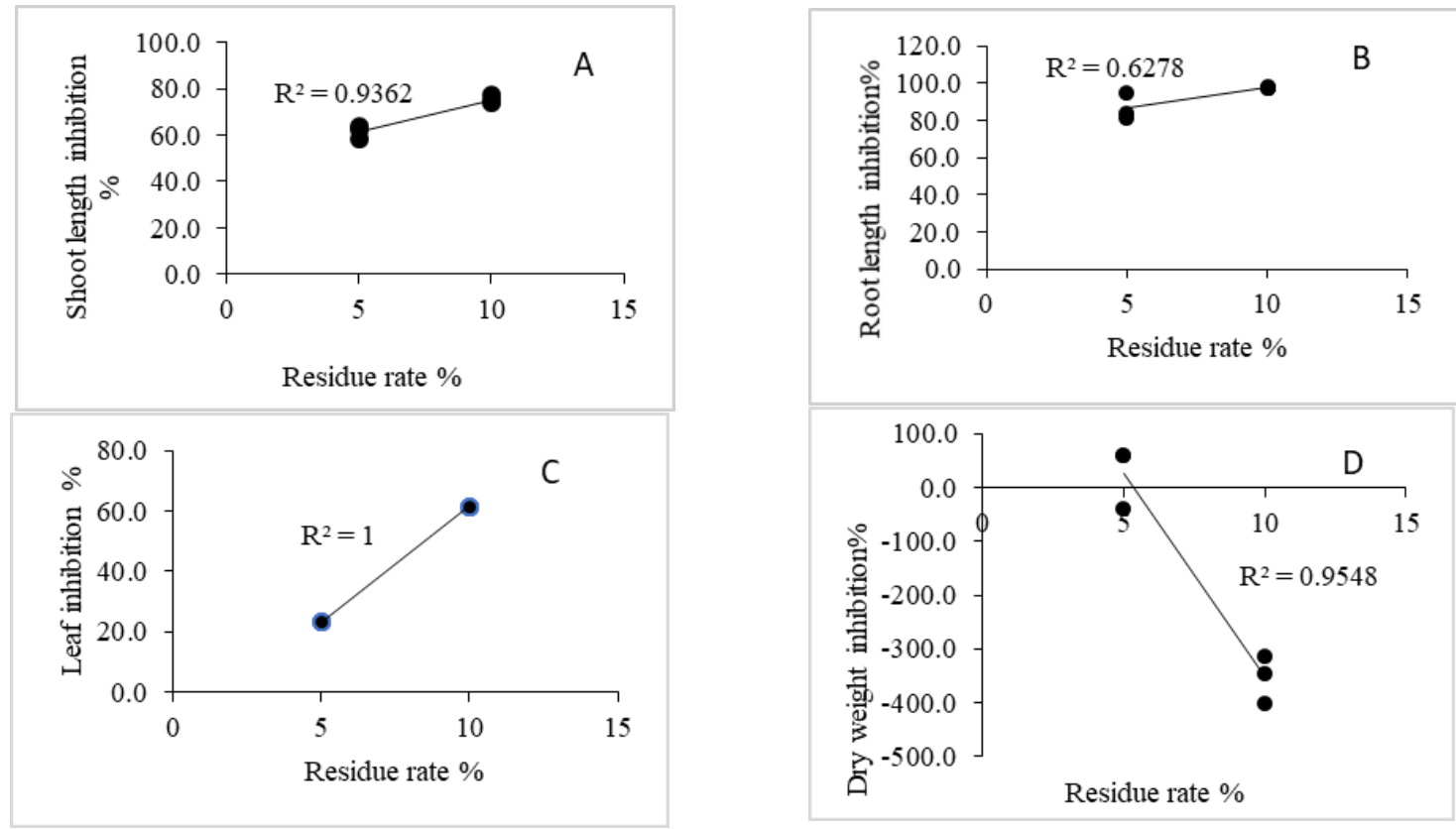

Figure 3: Correlation between $C$. argentea residue rates and inhibition of (A) shoot length, (B) root length (C) number of leaves per seedling, and (D) dry matter accumulation of paddy seedlings

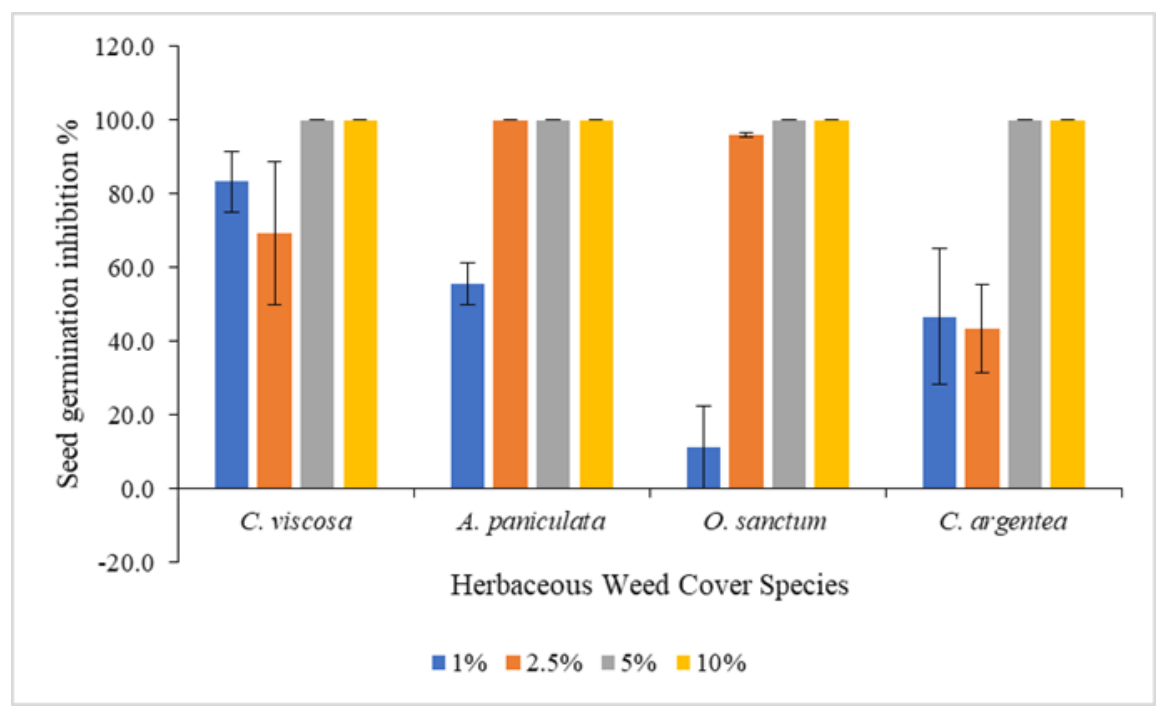

Figure 4: Inhibitory effect of different amounts $(1 \%, 2.5 \%, 5 \%$, and $10 \%$ ) of herbaceous weed residues on germination percentage of the same species.

include membrane permeability, water, and nutrient uptake, respiration, photosynthesis, protein and nucleic acid synthesis, and growth regulation in susceptible plants (Cheng and Cheng 2016). Seed germination and seedling growth of radish, field crops and herbaceous weed species showed significant reduction when increasing residue incorporation rates (Table 1). That means the concentration of allelochemicals released when decomposing residues have also been increased with the increase of the number of residues (Ranagalage et al. 2014). However, the release of these phytotoxic substances and their concentration is heavily affected by environmental conditions, e.g., drought, irradiation, competitors, nutrient limitation, temperature, disease, and pest damages. The 
Table 1: The inhibitory effect of herbaceous weed residues on growth and development of seedlings of radish and same species.

\begin{tabular}{|c|c|c|c|c|c|c|c|c|c|}
\hline \multirow{2}{*}{$\begin{array}{l}\text { Herbaceous } \\
\text { Weed Species }\end{array}$} & \multirow{2}{*}{$\begin{array}{l}\text { Resi- } \\
\text { due } \\
\text { rate }\end{array}$} & \multicolumn{4}{|c|}{ Radish } & \multicolumn{4}{|c|}{ Same weed species } \\
\hline & & ISL\% & IRL\% & IL\% & IDW\% & ISL\% & IRL\% & IL\% & IDW\% \\
\hline C. viscosa & $1 \%$ & $29.03^{\mathrm{ab}}$ & $20.13^{\mathrm{d}}$ & $-22.87^{\mathrm{def}}$ & $-106.03^{b}$ & $-715.33^{d}$ & $-119.67^{c}$ & $-314^{\mathrm{c}}$ & $-127.6^{\mathrm{a}}$ \\
\hline C. viscosa & $2.5 \%$ & $32.00^{\mathrm{ab}}$ & $9.83^{\mathrm{de}}$ & $-26.70^{\mathrm{ef}}$ & $-185.1^{c}$ & $-132.67^{b c}$ & $15.33^{\mathrm{ab}}$ & $29^{\mathrm{a}}$ & $62.3^{\mathrm{a}}$ \\
\hline C. viscosa & $5 \%$ & $36.13^{\mathrm{ab}}$ & $48.7^{\mathrm{c}}$ & $-13.23^{\text {cdef }}$ & $-37.63^{a b}$ & -NG- & -NG- & -NG- & -NG- \\
\hline C. viscosa & $10 \%$ & $49.97^{\mathrm{a}}$ & $98.8^{\mathrm{a}}$ & $26.13^{\mathrm{a}}$ & $54.40^{\mathrm{a}}$ & -NG- & -NG- & -NG- & -NG- \\
\hline A. paniculata & $1 \%$ & $-40.63^{d}$ & $8.1^{\mathrm{de}}$ & $-4.93^{\text {bcde }}$ & $-37.27^{\mathrm{ab}}$ & $52.33^{\mathrm{a}}$ & $33^{\mathrm{a}}$ & $0^{\mathrm{a}}$ & $49^{\mathrm{a}}$ \\
\hline A. paniculata & $2.5 \%$ & $-18.93^{\mathrm{cd}}$ & $-4.47^{\mathrm{e}}$ & $-4.933^{\text {bcde }}$ & $-28.07^{\mathrm{ab}}$ & -NG- & -NG- & -NG- & -NG- \\
\hline A. paniculata & $5 \%$ & $23.43^{\mathrm{ab}}$ & $73.57^{b}$ & $4.76^{\mathrm{bc}}$ & $37.73^{\mathrm{ab}}$ & -NG- & -NG- & -NG- & -NG- \\
\hline A. paniculata & $10 \%$ & $-\mathrm{D}-$ & $-\mathrm{D}-$ & $-\mathrm{D}-$ & $-\mathrm{D}-$ & -NG- & -NG- & -NG- & -NG- \\
\hline O. sanctum & $1 \%$ & $-12^{\mathrm{cd}}$ & $8.2^{\mathrm{de}}$ & $10.9^{\mathrm{ab}}$ & $14.77^{\mathrm{ab}}$ & $-282.33^{c}$ & $-281.67^{\mathrm{d}}$ & $-250^{\mathrm{bc}}$ & $-627^{b}$ \\
\hline O. sanctum & $2.5 \%$ & $4.20^{\mathrm{bc}}$ & $13.43^{\mathrm{de}}$ & $-3.53^{\mathrm{bcd}}$ & $-57.63^{\mathrm{abc}}$ & $-104^{a b}$ & $-37.33^{b}$ & $0^{\mathrm{a}}$ & $-309.7^{\mathrm{ab}}$ \\
\hline O. sanctum & $5 \%$ & $41.40^{\mathrm{a}}$ & $69.97^{\mathrm{bc}}$ & $-3.53^{b c d}$ & $4.97^{\mathrm{ab}}$ & -NG- & -NG- & -NG- & -NG- \\
\hline O. sanctum & $10 \%$ & $-\mathrm{D}-$ & -D- & $-\mathrm{D}-$ & $-\mathrm{D}-$ & -NG- & -NG- & -NG- & -NG- \\
\hline C. argentea & $1 \%$ & $29.53^{\mathrm{ab}}$ & $26.00^{d}$ & $-28.10^{f}$ & $-75.13^{\mathrm{abc}}$ & $-10^{\mathrm{ab}}$ & $-18^{a b}$ & $-88.67^{a b}$ & $-4^{\mathrm{a}}$ \\
\hline C. argentea & $2.5 \%$ & -NG- & -NG- & -NG- & -NG- & $-3^{a b}$ & $45.67^{\mathrm{a}}$ & $0^{\mathrm{a}}$ & $31.7^{\mathrm{a}}$ \\
\hline C. argentea & $5 \%$ & -NG- & -NG- & -NG- & -NG- & -NG- & -NG- & -NG- & -NG- \\
\hline C. argentea & $10 \%$ & -NG- & -NG- & -NG- & -NG- & -NG- & -NG- & -NG- & -NG- \\
\hline
\end{tabular}

Note: Inhibition percentages of shoot length (ISL\%), root length (IRL\%), number of leaves per seedling (IL\%), and dry weight (IDW\%). Positive values indicate inhibitory activity and negative values indicate promotion when compared to the corresponding controls (NG and D denoted by Not Germinated and Died respectively). Means with the same superscript in a column are not significantly different from each other while means with different superscripts are significantly different at $p<0.05$.
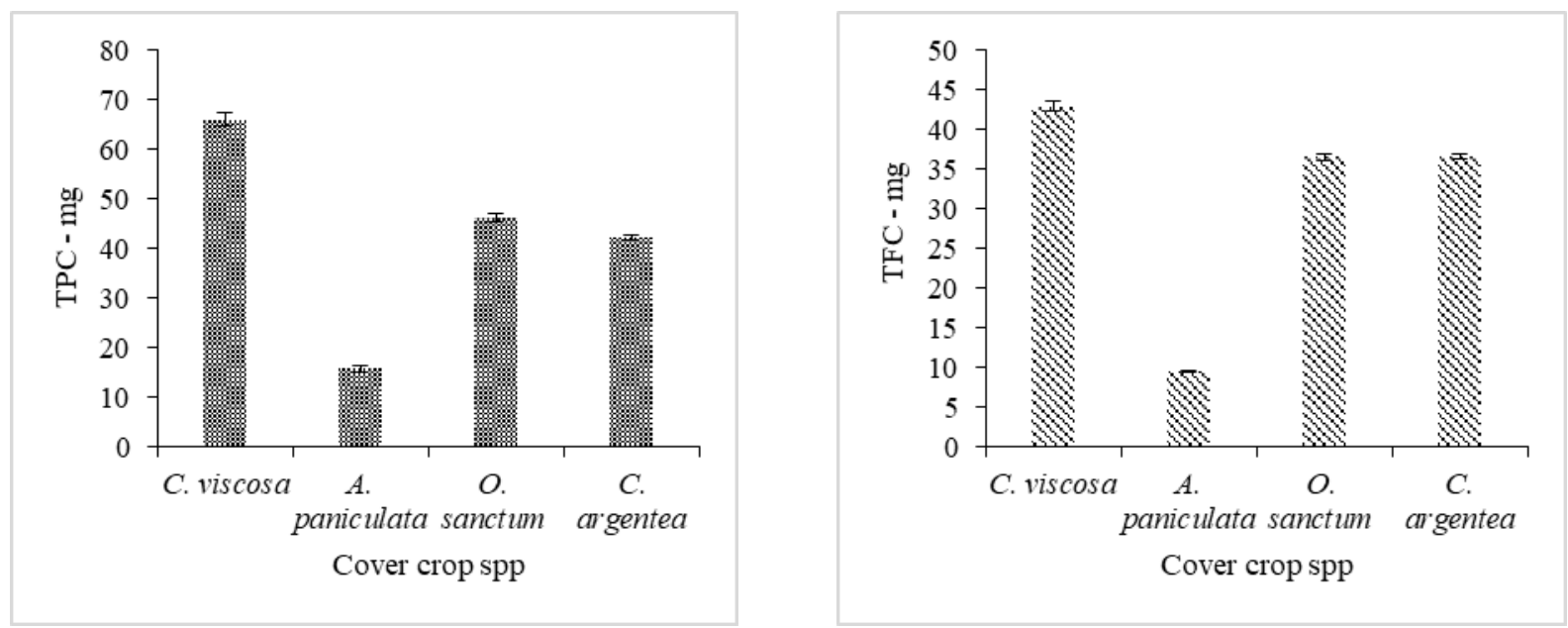

Figure 5: Total phenolic (TPC) and flavonoid contents (TFC) of selected cover crop species. 
maximum inhibition percentage of radish seed germination resulted in a $10 \%$ residue rate for all herbaceous weed residues except $C$. viscosa. C. argentea gave the highest GI\% for all residue rates except for $1 \%$ residue rate, which was $0 \%$. Moreover, among all treatments $10 \%$ residue rate of $C$. viscosa exhibit the highest inhibition percentage of growth and development of radish seedlings (Table 1). However, the dry matter accumulation and leaf growth of radish seedlings have been increased by $2.5 \%$ residue rate of all weed species rather than inhibition. Further, a hundred percent inhibition percentage of seed germination was observed in a $15 \%$ residue rate for all tested field crops by $C$. argentea (Fig.2). Ten percent residue rate also completely inhibits seed germination of field crop varieties except for paddy. Also, seedlings growth of paddy were highly positively correlated with $C$. argentea residue rate. But dry weight shows a strong negative relationship $\left(\mathrm{R}^{2}=0.95\right)$ with residue rate.

Autotoxicity is the beneficial or harmful effect of a plant species on itself. Also, autotoxicity is defined as intra-specific allelopathy which takes place when a plant releases a chemical substance that inhibits or delay germination and seedling growth of the other plant from the same species. In autotoxicity experiment also, a significant effect $\quad(p \leq 0.05) \quad$ was observed among herbaceous weed species and their application rates on the inhibition of seed germination (GI\%), shoot length (ISL\%), root length (IRL\%), and dry weight (IDW\%) of the same herbaceous weed species. Higher residue rates $(5 \%$ and $10 \%)$ of all tested species inhibited their seed germination by $100 \%$. Lower residue rates were also reduced the seed germination in a considerable percentage (more than 10\%). Although seed germination percentages are low in low residue rates, a lush stimulus growth was observed in seedlings of germinated seeds. Significantly highest shoot length reduction occurred only by $A$. paniculata $1 \%$ residue rate. All other rates of residues of herbaceous weed species stimulated shoot growth of the same species with significant differences. According to the results obtained in the present study, residues of four herbaceous weed species possessed allelopathic activity. The reduction in seed germination and seedling growth might be attributed to allelochemicals by interfering with major physiological processes of plant metabolism, viz. respiration and photosynthesis. Also, previous experiments have been reported the allelopathic activity of the above selected herbaceous weed species. As an example, Purohit and Pandya (2013) have also observed the inhibitory and stimulatory response of $O$. sanctum L. leaf extract for seed germination in common legumes (green gram, cowpea, pigeon pea, chickpea, black gram, and moth bean). As well as, the radicle and hypocotyl growth of all legumes had exhibited a stimulatory effect under lower concentrations (1\%). In 5\% concentration, green gram also showed stimulation for seedling growth. These results agree with the result of the present experiment.

Different plant species contain various allelochemicals in various concentrations (Xuan et al. 2004). In the present study significantly highest TPC and TFC were found in $C$. viscosa residue followed by $O$. sanctum and $C$. argentea and significantly lowest TPC and TFC were found in $A$. paniculata. The presence of allelochemicals, flavonoids, and saponins in root, stem, and leaves of $C$. viscosa was identified by Kavitha (2017), where the presence of alkaloids in those plant parts was identified by Wagner's test. The paper stated that Dragendorff's test was not detected alkaloids in the same plant parts. In the present investigation, Dragendorff's test was used for the analysis of alkaloid. Hence, that may be the reason for the absence of alkaloids in the present investigation. Reigosa et al. (1999) have reported that low molecular weight phenolics are well-known allelochemicals and the effect of phenolic acids is more on seedling growth than germination. The result of the present study agrees with that statement, the highest inhibition of root and shoot length in radish were observed in C. viscosa residue treatment (Table 01). Moreover, the result of the present study agrees with Reigosa et al. (1999) 
findings, where the highest concentration of the compounds inhibited the seed germination and seedling growth of radish, nevertheless lower concentrations showed the stimulatory effect.

\section{CONCLUSION}

Four herbaceous weed species (C. viscosa, $A$. paniculata, $O$. sanctum, and $C$. argentea) used in this experiment would be able to inhibit seed germination and growth of radish and the same species itself. Further, slashing and addition of $C$. argentea will seriously affect succeeding field crops such as finger millet, cowpea, mungbean, and black gram. Phenolic acids identified in herbaceous weed may affect the seedling growth of indicator plant. Hence, it can be concluded that the frequent mowing and incorporation of residues of the above-selected weed species to the orchard floor can be used as an alternative weed management method but it might affect the growth and development of subsequent crops.

\section{AUTHOR CONTRIBUTION}

AJMCMS, DLW and HKMSK conceptualized and designed the study. AJMCMS performed the experiments. AJMCMS, DLW and HKMSK analyzed and interpret the data. AJMCMS and DLW contributed in drafting the manuscript and DLW critically revised the manuscript.

\section{REFERENCES}

Abeysekera WPKM, Arachchige SPG and Ratnasooriya WD 2017 Bark extracts of Ceylon cinnamon possess antilipidemic activities and bind bile acids in vitro. Evidence-Based Complementary and Alternative Medicine, 2017:1-10.

Ahuja I, Kissen R and Bones AM 2012 Phytoalexins in defense against pathogens. Trends in plant science, 17 (2):73-90.

Ali KA 2021 Allelopathy Index: a new mathematical assessment method for allelopathy studies. Zanco Journal of Pure and Applied Sciences, 33:1-18.

Baličević R, Ravlić M and Ravlić I 2015 Allelopathic effect of aromatic and medicinal plants on Tripleurospermum inodorum (L.) $\mathrm{CH}$ Schultz. Herbologia, 15(2):40-53.

Cheng F and Cheng Z 2016 Corrigendum: Research Progress on the use of Plant Allelopathy in Agriculture and the Physiological and Ecological Mechanisms of Allelopathy. Frontiers in Plant Science, 7:1697.

Chung I-M and Miller DA 1995 Allelopathic Influence of Nine Forage Grass Extracts on Germination and Seedling Growth of Alfalfa. Agronomy Journal, 87(4):767.

Einhellig FA 1995 Mechanism of action of allelochemicals in allelopathy. ACS Symposium Series. American Chemical Society: Washington, DC, pp. 96-116.

Farooq M, Jabran K, Cheema ZA, Wahid A and Siddique KH 2011 The role of allelopathy in agricultural pest management. Pest management science, 67(5):493-506.

Hossain M, Urbi Z, Sule A and Rahman K 2014 Andrographis paniculata (Burm. f.) Wall. ex Nees: a review of ethnobotany, phytochemistry, and pharmacology. The Scientific World Journal, 2014:1-28.

Islam A and Kato-Noguchi H 2014 Phytotoxic activity of Ocimum tenuiflorum extracts on germination and seedling growth of different plant species. The Scientific World Journal, 2014:1-8

Jana A and Biswas SM 2011 Lactam nonanic acid, a new substance from Cleome viscosa with allelopathic and antimicrobial properties. Journal of Biosciences, 36(1):27-35.

Kavitha D 2017 Qualitative and Gc-Ms Analysis of Phytochemical Constituents of Tick Weed (Cleome viscosa L.). Kongunadu Research Journal, 4(2):167-172.

Kengar YD 2018 Allelopathic Potentiality of Celosia argentea L Review. Current Investigations in Agriculture and Current Research, 1(2):36-39.

Latif S, Chiapusio G and Weston LA 2017 Allelopathy and the Role of Allelochemicals in Plant Defence, In: 
Becard, G. (ed.) Advances in Botanical Research. Academic Press, pp. 19-54

Nagaraja T and Deshmukh S 2009 Phytotoxic effect of Andrographis paniculata Nees on metabolism of Parthenium hysterophorus L. Journal of Biopesticides, 2(2):165-167.

Ozkan TGI, Urusak EA, Appiah KS and Fujii Y 2019 First Broad Screening of Allelopathic Potential of Wild and Cultivated Plants in Turkey. Plants, 8 (12):532.

Pattanayak P, Behera P, Das D and Panda SK 2010 Ocimum sanctum Linn. A reservoir plant for therapeutic applications: An overview. Pharmacognosy reviews, 4(7): 95105.

Purohit S and Pandya N 2013 Allelopathic activity of Ocimum sanctum L. and Tephrosia purpurea (L.) Pers. Leaf extracts on a few common legumes and weeds. International Journal of Research in Plant Science, 3(1):5-9.

Putnam AR and Duke WB 1978 Allelopathy in Agroecosystems. Annual Review of Phytopathology, 16(1):431-451.

Ranagalage A, Jayakody $\mathrm{T}$ and Wathugala DL 2014 Allelopathic potential of rice residues of selected rice varieties (Oryza sativa L.) against Echinochloa crus-galli. Journal of Tropical Forestry and Environment, 4:24-30.

Reigosa M, Souto X and Gonz L 1999 Effect of phenolic compounds on the germination of six weeds species. Plant Growth Regulation, 28(2):83-88.

Reigosa MJ, Pedrol N and González L 2006 Allelopathy: a physiological process with ecological implications. Springer Science and Business Media. P.O. Box 17, 3300 AA Dordrecht, The Netherlands, pp. 1-61.

Saritha P and Sreeramulu A 2013 Allelopathic effects of Celosia argentea L. root extracts on crop plant seed germination. International Journal of Life sciences Biotechnology and Pharma Research, 2(1):142-154.

Sharma RK, Pandey B and Uniyal S 2017 Phytotoxicity: An Essential Tool in
Ecological Risk Assessment. In: Chandra R, Dubey NK and Kumar V (eds.) Phytoremediation of Environmental Pollutants. CRC Press, 6000 Broken Sound Parkway NW, Suite 300 Boca Raton, FL, pp. 363.

Shinwari M and Fujii Y 2013 Allelopathic activity of medicinal plants and weeds from Pakistan. Allelopathy Journal, 32 (2):223-232.

Siddhuraju P and Becker K 2003 Antioxidant properties of various solvent extracts of total phenolic constituents from three different agroclimatic origins of the drumstick tree (Moringa oleifera Lam.) leaves. Journal of agricultural and food chemistry, 51(8):2144-2155.

Singh H, Mishra A, Mishra AK 2015 Cleome viscosa Linn (Capparaceae): A Review. Pharmacognosy Journal, 7 (6):326-329.

Singh HP, Batish DR and Kohli RK 1999 Autotoxicity: concept, organisms, and ecological significance. Critical Reviews in Plant Sciences, 18(6):757772.

Singleton VL, Orthofer R and LamuelaRaventós RM 1999 Analysis of total phenols and other oxidation substrates and antioxidants by means of folinciocalteu reagent. Methods in enzymolog, 299:152-178.

Sreevidya N and Mehrotra S 2003 Spectrophotometric method for estimation of alkaloids precipitable with Dragendorff's reagent in plant materials. Journal of AOAC international, 86(6):1124-1127.

Trezzi MM, Vidal RA, Junior AAB, Bittencourt HVH and Filho APDSS 2016 Allelopathy: driving mechanisms governing its activity in agriculture. Journal of Plant Interactions, 11(1): 53 -60 .

Xuan TD, Tsuzuki E, Hiroyuki T, Mitsuhiro M, Khanh TD and Chung IM 2004 Evaluation on phytotoxicity of neem (Azadirachta indica. A. Juss) to crops and weeds. Crop protection, 23(4):335 -345 . 